\title{
EVIDENCE AS A CATEGORY OF CRIMINAL PROCEDURE LAW: NEW (OLD) APPROACHES
}

\author{
Valentina A. Lazareva \\ Samara National Research University named after Academician S.P. Korolev, Samara, Russian Federation
}

Introduction: in the science of criminal procedure there was a strongly held view of evidence as a product of cognitive activity of the investigator (inquiry officer) and the investigative action as the main method of collecting evidence. In accordance with these views, the evidence on the basis of which the circumstances relevant to the criminal case should be established is a combination of information on the actual circumstances of the case and the form of action in which this information can be stored in the criminal case file. The obtaining of such information and its form of action fall within the exclusive competence of the preliminary investigation bodies. Therefore, for many years, the law enforcement officer has formed an idea of the identity of investigative and judicial evidence, virtually precluding the possibility of challenging them both on the grounds of unreliability and inadmissibility.

The development of the principle of controversy in the criminal process led to the extension of the methods of collecting evidence and persons concerning the collection of evidence, which questioned the concept of forming evidence by the preliminary investigation bodies. In this regard, the author sets a goal to analyze the compliance of the concept of evidence formation with the principles and norms of the current Code of Criminal Procedure and to justify a new approach to the understanding of evidence.

To achieve this goal, the general scientific research methods were used: analysis, synthesis, description, comparison, classification, systematization and generalization. As a result, the author's understanding of evidence as the information about the circumstances relevant to the case is presented, which allows distinguishing evidence from the methods of its collection and makes it possible to increase the adversarial efficiency of criminal proceedings.

Conclusions: as a result of the study, the concept of evidence corresponding to the adversarial principle is formulated, the difference between evidence and admissible evidence is justified, the prospects for improving the process of verification and evaluation of evidence, further development of the methods of collecting evidence are shown, which is important for improving the quality of training of students in the field of "Jurisprudence", qualification of teachers of law schools, as well as the effectiveness of the law enforcement practice.

Key words: evidence, formation of evidence, methods of collecting evidence, sources of evidence, evaluation of evidence, investigating judge, adversariality, equality of the parties.

Citation. Lazareva V.A. Evidence as a Category of Criminal Procedure Law: New (Old) Approaches. Legal Concept, 2019, vol. 18, no. 2, pp. 55-62. (in Russian). DOI: https://doi.org/10.15688/lc.jvolsu.2019.2.8

\section{ДОКАЗАТЕЛЬСТВО КАК КАТЕГОРИЯ УГОЛОВНО-ПРОЦЕССУАЛЬНОГО ПРАВА: НОВЫЕ (СТАРЫЕ) ПОДХОДЫ}

\section{Валентина Александровна Лазарева}

\author{
Самарский национальный исследовательский университет им. акад. С.П. Королева,
} г. Самара, Российская Федерация 
ние сведений о фактических обстоятельствах дела и той процессуальной формы, в которой эти сведения могут сохраняться в материалах уголовного дела. Получение таких сведений и придание им процессуальной формы относится к исключительной компетенции органов предварительного расследования. Поэтому в течение многих лет у правоприменителя формировалось представление о тождественности следственных и судебных доказательств, фактически исключающее возможность оспаривания их как по мотиву недостоверности, так и по мотиву недопустимости.

Развитие состязательного начала в уголовном процессе привело к расширению способов собирания доказательств и лиц, имеющих отношение к их собиранию, что поставило под сомнение концепцию формирования доказательств органами предварительного расследования. В связи с этим автором была поставлена цель проанализировать соответствие концепции формирования доказательств принципам и нормам действующего УПК РФ и обосновать новый подход к пониманию доказательства.

Для достижения поставленной цели были использованы общенаучные методы исследования: анализ, синтез, описание, сравнение, классификация, систематизация и обобщение. В результате представлено авторское понимание доказательств, как сведений об обстоятельствах, имеющих значение для дела, что позволяет отделить доказательства от способов их собирания и дает возможность повысить состязательную эффективность уголовного судопроизводства.

Выводы: в результате исследования сформулировано соответствующее принципу состязательности понятие доказательства, обосновано различие между доказательствами и допустимыми доказательствами, показаны перспективы совершенствования процесса проверки и оценки доказательств, дальнейшего развития способов собирания доказательств, что имеет значение для повышения качества обучения студентов по направлению подготовки «Юриспруденция», квалификации педагогических работников юридических вузов, а также эффективности правоприменительной практики.

Ключевые слова: доказательство, формирование доказательств, способы собирания доказательств, источники доказательств, оценка доказательств.

Цитирование. Лазарева В. А. Доказательство как категория уголовно-процессуального права: новые (старые) подходы // Legal Concept = Правовая парадигма. $-2019 .-$ T. 18, № 2. - C. 55-62. - DOI: https://doi.org/ 10.15688/lc.jvolsu.2019.2.8

\section{Введение}

Мы привыкли считать, что уголовнопроцессуальная деятельность детально урегулирована законом, соблюдение которого обеспечивает как законность производства по уголовному делу, так и его эффективность, является гарантией прав лиц, заинтересованных в его результатах. Закон определяет порядок осуществления уголовно-процессуальной деятельности, процедуру каждого процессуального действия, содержание каждого процессуального решения, основания его принятия и отмены, обязанность и порядок разъяснения обвиняемому как комплекса предоставляемых прав, так и каждого права в отдельности. Закон определяет понятие и виды доказательств, служащих основаниями принятия решений, требования, которым они должны соответствовать, порядок получения и оформления.

Детальная урегулированность уголовнопроцессуальных отношений, однако, не объективирует процессуальную деятельность и достигнутый результат. Действуя в строгом со- ответствии с требованиями УПК, властные субъекты уголовного процесса вносят в процессуальную деятельность изрядную долю субъективного усмотрения. Мы не имеем здесь в виду зависимость усмотрения от связанных с субъектом негативных факторов, побуждающих его действовать в разрез с требованиями закона или обусловливающих познавательные ошибки. Мы лишь обращаем внимание на необходимость учитывать, что право реализуется не само по себе, а через действия людей, его применяющих, использующих, соблюдающих или нарушающих. Сказанное в полной мере относится и к такой категории уголовно-процессуального права, как доказательство.

\section{Нормативное определение понятия доказательства}

Двойственное определение доказательства в ст. 69 УПК РСФСР, перенесенное затем в ст. 74 УПК РФ, привело к формированию в теории уголовного процесса представления о доказательствах как неразрывном 
единстве содержания и формы. При этом считается, что содержание доказательства объективно, поскольку оно отражает реальность, а форма фетишизируется, поскольку ее отсутствие исключает возможность использовать какие бы то ни было сведения о совершенном преступлении. В действительности же и содержание и форма доказательства являются предметом проверки и оценки, осуществляемой субъектами, к которым закон относит органы предварительного расследования, прокурора и суд.

Форма доказательства постепенно вышла за рамки средства сохранения информации и вобрала в себя всю процедуру ее собирания, в первую очередь процедуру производства следственных действий как основного, практически единственного по УПК РСФСР способа собирания доказательств. Достаточно сказать, что такие способы собирания доказательств, как их представление и истребование, предусмотренное ст. 70 УПК РСФСР, зачастую рассматривались как формирующиеся следственные действия. Представление о доказательстве как результате следственной деятельности обусловило возможность научного обоснования теории, получившей название «концепция формирования доказательств», имеющей много последователей до настоящего времени $[1$, c. $124-$ $130 ; 7$, с. $10 ; 9$, с. 70].

В соответствии с этой концепцией доказательства, на основе которых должны устанавливаться имеющие значение для уголовного дела обстоятельства, получают форму (вид) показаний, заключений, протоколов и т. п. в ходе следственных и некоторых иных процессуальных действий, представляющих собой систему регламентированных уголовнопроцессуальным законом и осуществляемых следователем (судом) поисковых, познавательных и удостоверительных операций, которые приспособлены к эффективному отысканию, восприятию и закреплению содержащейся в следах преступления доказательственной информации [14, с. 38]. Отсюда следует, что доказательствами являются не сами по себе сведения о тех или иных обстоятельствах, а сведения, которые обнаружены, извлечены и закреплены в материалах уголовного дела субъектом уголовно-процессуаль- ной деятельности в соответствии с требованиями УПК [15, с. 18]. В понятие доказательства, таким образом, включаются признаки, предопределяющие его оценку как допустимого доказательства. Доказательства следственные автоматически становятся доказательствами судебными, поскольку существует презумпция их допустимости, на что, собственно, и указывает формулировка ч. 2 ст. 74 УПК РФ - «в качестве доказательств допускаются» и т. п. Сведения, которые получены субъектами уголовного процесса, не имеющими полномочий на проведение следственных действий, не считаются допустимыми, как не имеющие надлежащей процессуальной формы, хотя могут быть признаны доказательствами лишь после их проверки органами предварительного расследования или судом. Такой подход к пониманию доказательства обессмысливает институт оценки доказательств, умаляет роль стороны защиты в формировании доказательственной базы по уголовному делу, уничтожает ее право на представление доказательств, дискредитирует принципы независимости суда и состязательности судопроизводства.

\section{Критика концепции}

\section{формирования доказательств}

Рассмотренный выше подход не соответствует реальности.

Во-первых, он не универсален, не применим к целому ряду доказательств, которые достаются следователю в готовом виде, формируются без участия следователя и в дополнительном формировании (доформировании) не нуждаются. Это вещественные доказательства, иные документы и заключения специалистов. Конструкция их «доформирования» путем «тщательного», как рекомендуется, осмотра и вынесения постановления о признании предмета или документа вещественным доказательством искусственна, мнима, говоря словами С.Б. Россинского, представляет собой «теоретический фантом» $[8$, с. 9]. Данным постановлением лишь обозначается процессуальный статус объекта, который вводится, включается в материалы уголовного дела; а протокол его осмотра является самостоятельным источником информации. Что 
касается иных документов и заключений специалиста, то к ним даже такие действия не применяются, но при этом они приобщаются к материалам дела, исследуются в судебном заседании в ходе судебного следствия и оцениваются по правилам, установленным для оценки доказательств.

Столь же искусственной является попытка применить концепцию формирования доказательств к результатам оперативно-розыскной деятельности (ст. 89 УПК), информации о соединениях между абонентами и абонентскими устройствами (ст. 186.1 УПК), результатам контроля и записи телефонных или иных переговоров (ст. 186 УПК), искусственно причисленных к вещественным доказательствам, и даже к такому виду доказательства, как заключение эксперта. Получение информации указанными способами не имеет ничего общего с классическим следственным действием, суть которого составляет познавательный процесс восприятия, посредством которого происходит двойное преобразование информации, фиксируемой затем с помощью протокола и иногда технических средств [15, с. $15-$ 16]. Во всех указанных случаях следователь не вступает в контакт с непосредственным источником информации, он получает (принимает) и использует в качестве доказательства информацию, выявленную и соответствующим образом оформленную другим субъектом за рамками уголовно-процессуальной деятельности и процессуальной формы и даже не всегда в связи с ее производством. Таким образом, доказательствами, сформированными следователем, можно считать лишь протоколы следственных действий, сохраняющих воспринятую и преобразованную следователем первичную информацию - протокол осмотра места происшествия, следственного эксперимента, предъявления для опознания, обыска. Усилиями следователя в этих случаях и создается информационный продукт в единстве его формы и содержания.

Протоколы допроса и очной ставки не являются самостоятельным видом доказательств, поскольку доказательствами в ст. 7480, 276, 282 УПК РФ названы показания свидетеля, потерпевшего, обвиняемого, подозреваемого, эксперта и специалиста, а не содержащие эти показания протоколы. В своих пре- дыдущих публикациях мы отмечали, что показания как вид доказательства не только возникают, но и существуют лишь в тот момент, когда лицо излагает информацию, которую сохраняет его память, сведения, недоступные непосредственному восприятию субъекта, показаниями не являются [2, с. 19]. Поэтому показания, полученные и преобразованные в протокол допроса следователем или дознавателем, не являются по общему правилу доказательствами для суда, который в силу требований ст. 240 УПК РФ обязан лично допросить лиц, владеющих информацией, имеющей значение для дела. Выносить же судебное решение о виновности подсудимого на основании следственных протоколов, содержащих полученные от свидетелей и потерпевших устные сообщения, в состязательном уголовном судопроизводстве невозможно, хотя закон и допускает возможность оглашения при определенных обстоятельствах протоколов следственных допросов. Тем не менее вопрос этот не бесспорен, ст. 281 уже на этапе введения в действие УПК РФ подвергалась изменениям, а в 2016 г. была дополнена ст. 2.1, позволяющей оглашать показания ранее (следователем, дознавателем) допрошенных и не явившихся в суд свидетелей и потерпевших лишь при условии предоставления обвиняемому (подсудимому) в предыдущих стадиях производства по делу возможности оспорить эти доказательства предусмотренными законом способами, например, путем допроса источника сведений на очной ставке. Этот шаг можно считать, хотя и недостаточной, но все же очевидной попыткой обеспечить непосредственность исследования судом доказательств. Фактически законодатель не только отказал протоколу допроса свидетеля в статусе доказательства, но и отказал следователю в праве формировать такое доказательство, сделал шаг в сторону отказа от отождествления судебных доказательств, как единственного основания судебного решения, и доказательств следственных.

Концепция формирования доказательств значительно утратила свои позиции и в результате «распроцессуаливания» формы получения доказательственной информации в связи с введением в 2013 г. сокращенного дознания и обусловленного этим расширения возмож- 
ностей так называемой доследственной проверки. Хотя ст. 144 УПК РФ и указывает на необходимость соблюдения в процессе получения информации о наличии или отсутствии признаков преступления «порядка, установленного настоящим кодексом», большинство проверочных действий не обладает достаточными гарантиями ее достоверности, поэтому при проведении дознания в сокращенной форме она принимается в качестве доказательства только при условии отсутствия возражений стороны защиты. Тем не менее, поскольку ст. 144 УПК РФ регулирует проверку оснований к возбуждению всех уголовных дел, а не только расследуемых в сокращенной форме дознания, лишение способа собирания доказательств значения элемента процессуальной формы доказательств стало еще более очевидным. Столь же очевидной становится разница между доказательством, полученным любым из перечисленных процессуальных действий, и допустимым доказательством. Первое используется для выдвижения и проверки подозрения, формулирования и предъявления обвинения, второе представляется в суд, исследуется в судебном заседании и используется для обоснования приговора.

\section{Концепции}

\section{формирования доказательств \\ в свете принципа состязательности уголовного судопроизводства}

Возникшая в период действия УПК РСФСР, принятого в 1960 г., концепция формирования доказательств «работала» на тезис об общих целях и задачах органов предварительного расследования и суда - быстро и полно раскрыть преступление, изобличить виновного, не допустить, чтобы виновный ушел от ответственности, а невиновный был осужден, для чего исследовать обстоятельства дела полно, объективно и всесторонне. То, что результаты познавательной и удостоверительной деятельности следователя (дознавателя) признаются доказательствами и в суде, фактически судебными доказательствами, в этих условиях было закономерно.

Несомненно, на таком понимании результатов деятельности следователя некоторым образом сказывалось влияние Устава уголов- ного судопроизводства, которым следователь принадлежал к судебной власти, в связи с чем полученные им доказательства признавались судебными. Но отнесение следователя к стороне обвинения сделало конфликт между системой принципов уголовного процесса и концепцией формирования доказательств неизбежным. Согласиться с тем, что доказательства, на основе которых формируется внутреннее убеждение суда, есть продукт деятельности органа уголовного преследования, значит, отрицать и равноправие сторон, и независимость суда от одной из этих сторон - положения, составляющие суть принципа состязательности.

Отнесенный к стороне обвинения следователь не может претендовать на роль беспристрастного субъекта, а результаты осуществляемой им познавательной деятельности на роль судебных доказательств. Процессуальная форма познавательной деятельности дознавателя, следователя не может претендовать на роль инструмента, обеспечивающего достоверность, правильность, объективность содержания доказательственной информации, поскольку самому субъекту познания на законодательном уровне отказано в привилегии считаться более объективным и незаинтересованным, чем вторая сторона.

Высказывая свое отношение к этой концепции, мы постоянно подчеркивали, что формирование доказательства состоит не только в придании информации процессуальной формы. Содержащаяся в следах преступления информация не переносится в материалы уголовного дела механически, а отражаясь вначале в сознании познающего субъекта, а затем - в материалах дела, не только преобразуется по форме, но изменяется и по содержанию. Наиболее заметно это при формировании так называемых вербальных доказательств - в протоколе допроса отражается не психический образ воспринятого лицом и преобразованного в его устную речь события, а преобразованный в письменную речь образ события, сформированный в сознании допрашивающего лица в процессе восприятия устной речи допрашиваемого. Иными словами, протокол следственного действия не является механическим отражением следов преступления, воспринятых субъектом, 
проводившим следственное действие непосредственно (осмотр) или опосредованно (допрос). Сформированные следователем доказательства есть в значительной мере продукт его субъективного восприятия тех или иных событий, действий, объектов, несущий отпечаток не только общих закономерностей и индивидуальных особенностей восприятия, но и выполняемой этим субъектом функции. Получая готовые, то есть сформированные органами предварительного расследования, доказательства, суд попадает в зависимость от них и от подтверждаемого ими обвинительного тезиса.

Продолжая утверждать, что доказательства - это оформленный в соответствии с требованиями УПК познавательный образ отразившихся в сознании следователя следов преступления, мы должны были бы признать фиктивность многих обусловленных принципом состязательности правил - о разделении процессуальных функций, о равноправии сторон, о собирании и представлении доказательств обвиняемым и потерпевшим, защитником и представителем, не имеющими полномочий по формированию доказательств.

Очевидная несовместимость концепции формирования доказательств с принципом состязательности уголовного судопроизводства не может быть преодолена предлагаемым в теории возложением на следователя дополнительной обязанности всесторонне, полно и объективно исследовать все входящие в предмет доказывания обстоятельства или пересмотром функции следователя путем исключения его из числа участников процесса на стороне обвинения [13, с. 133]. Но возможно, поменяв подход к пониманию самого доказательства, мы сможем по-иному взглянуть и на процесс его формирования.

Ранее мы неоднократно указывали на необходимость разделять собственно доказательство, как информационный продукт, и то, что мы привыкли называть его процессуальной формой [3] и что, по сути, является процедурой получения информации о преступлении, вычленять в этом единстве формы и содержания его аргументационную составляющую, то есть информацию, или, языком УПК, сведения об обстоятельствах, имеющих значение для дела (фактические данные, если вспомнить ст. 69 УПК РСФСР), служащую фактологическим основанием судейского убеждения [11, с. 17].

Лишь при таком понимании доказательства обретает смысл термин «источник доказательства», по поводу которого в теории до сих пор не сложилось консенсуса. Источник доказательства как источник сведений (фактических данных) об обстоятельствах, имеющих значение для дела, сам доказательством являться не может, хотя начиная с М.С. Строговича, источник доказательства отождествляется с самим доказательством, взятым со стороны его процессуальной формы [12]. Так называемая двойственная концепция доказательств М.С. Строговича, впоследствии раскритикованная сторонниками единого понятия, может служить основой разделения доказательств на следственные и судебные [6]: сформированные следователем доказательства не являются в силу приведенных выше причин доказательствами для суда, но служат для него источниками сведений (фактических данных), которые после их исследования в состязательной судебной процедуре и становятся судебными доказательствами. Суд основывает свои выводы о виновности или невиновности подсудимого исключительно на основании собственного восприятия информации, извлеченной им непосредственно из памяти физических лиц, из предметов и документов. В процессе исследования источников доказательств происходит формирование внутреннего судейского убеждения как совокупности неопровергнутых знаний об обстоятельствах преступления, которым в теории придается значение доказательственных фактов.

Подобные взгляды получают все большее распространение [4, с. 34; 10, с. 50-51]. В частности, в недавнем диссертационном исследовании А.О. Машовец формулируется вывод: «Собранные (сторонами) во время досудебного производства фактические материалы - это не доказательства, а совокупность средств хранения и передачи информации, из которых посредством следственных действий, проводимых в судебном заседании, формируются судебные доказательства... В судебном следствии фактические материалы должны превращаться в доказательства 
B.A. Лазарева. Доказательство как категория уголовно-процессуального права: новые (старые) подходы

обвинения или доказательства защиты, то есть средства убеждения, под воздействием которых и формируется внутреннее убеждение судьи, обязанного сохранять беспристрастность и независимость» [5, с. 15].

Такой подход к пониманию сущности доказательств меняет наши представления и о процедуре их формирования. Признав, что суд получает от органов предварительного расследования не доказательства, а их источники, в процессе исследования которых формируются судебные доказательства, мы обеспечили бы большую свободу судейского убеждения и независимость суда от органов уголовного преследования.

\section{Выводы}

Основанное на принципе состязательности уголовное судопроизводство требует иного, чем прежде, подхода к пониманию доказательства. Доказательствами по уголовному делу, как единственным основанием внутреннего убеждения суда, выступает информация, полученная судом из представленных сторонами источников, ни один из которых не должен иметь предустановленной силы. Развитие уголовно-процессуальной теории в указанном направлении способно в перспективе оказать существенное влияние на эффективность следственной и объективность судебной практики.

\section{СПИСОК ЛИТЕРАТУРЫ}

1. Доля, Е. А. О собирании и формировании доказательств по УПК РФ / Е. А. Доля // Новый Уголовно-процессуальный кодекс России в действии : материалы круглого стола, 13 нояб. 2003 г. - М. : ТК Велби : Проспект, 2004. - 192 с.

2. Лазарева, В. А. Проблемы использования свидетельских показаний в уголовном процессе / В. А. Лазарева, Д. В. Попов. - М. : Юрлитинформ, 2009. - $160 \mathrm{c}$.

3. Лазарева, В. А. Трансформация понятия «доказательство» в состязательном уголовном процессе / В. А. Лазарева // Вектор науки Тольяттинского государственного университета. Серия: Юридические науки. - 2017. - № 2 (29). - С. 39-43.

4. Макаркин, А. И. Состязательность на предварительном следствии / А. И. Макаркин. - СПб. : Юридический центр Пресс, 2004. - 265 с.
5. Машовец, А. О. Теоретическая модель правовой организации судебного следствия в уголовном процессе Российской Федерации : автореф. дис. ... д-ра юрид. наук / Машовец Асия Океановна. - Екатеринбург, 2018. - 42 с.

6. Михайловская, И. Б. Соотношение судебных и следственных доказательств / И. Б. Михайловская // Государство и право. - 2006. - № 9. - С. 39-47.

7. Михеенко, М. М. Доказывание в советском уголовном процессе / М. М. Михеенко. - Киев : Вища шк., 1864. - 133 с.

8. Россинский, С. Б. Следственные действия / С. Б. Россинский. - М. : Норма, 2018. - 240 с.

9. Семенцов, В. А. Следственные действия в досудебном производстве / В. А. Семенцов. - М. : Юрлитинформ, 2017. - 254 с.

10. Смирнов, А. В. Модели уголовного процесса / А. В. Смирнов. - СПб. : Наука, 2000. - 224 с.

11. Спасович, В. Д. Избранные труды и речи / В. Д. Спасович. - Тула : Автограф, 2000. - 496 с.

12. Строгович, М. С. Курс советского уголовного процесса : в 2 т. Т. 1 / М. С. Строгович. - М. : Наука, 1968. - 330 с.

13. Шейфер, С. А. Досудебное производство в России: этапы развития следственной, судебной и прокурорской власти / С. А. Шейфер. - М. : Норма, 2013. - 192 c.

14. Шейфер, С. А. Следственные действия. Система и процессуальная форма / С. А. Шейфер. М. : Юрлитинформ, 2001. - 208 с.

15. Шейфер, С. А. Сущность и способы собирания доказательств в советском уголовном процессе / С. А. Шейфер. - М. : Изд-во ВЮЗИ, 1972. $130 \mathrm{c}$.

\section{REFERENCES}

1. Dolya E.A. On the Collection and Formation of Evidence on the Code of Criminal Procedure. New Criminal Procedure Code of Russia in Action. Materials of the Round Table on November 13, 2003. Moscow, TK Velbi. Publishing house, Prospect Publ., 2004. 192 p. (in Russian).

2. Lazareva V.A., Popov D.V. Problems of Using Testimony in Criminal Proceedings. Moscow, Yurlitinform Publ., 2009. 160 p. (in Russian).

3. Lazareva V.A. Transformation of the Notion "Proof" in Adversarial Criminal Proceedings. Vector of Science of Togliatti State University. Series: Legal Sciences, 2017, no. 2 (29), pp. 39-43. (in Russian).

4. Makarkin A.I. Competitiveness of the Preliminary Investigation. Saint Petersburg, Law center Press, 2004. 265 p. (in Russian).

5. Mashovets A.O. Theoretical Model of Legal Organization of Judicial Investigation in the Criminal 
Process of the Russian Federation: abstract. dis. ... d-ra yurid. sciences. Ekaterinburg, 2018. 42 p. (in Russian).

6. Mikhailovskaya I.B. The Ratio of Judicial and Investigative Evidence. State and law, 2006, no. 9, pp. 39-47. (in Russian).

7. Mikheenko M.M. Proof in the Soviet Criminal Process. Kiev, Vishcha shk. Publ., 1864. 133 p. (in Russian).

8. Rossinsky S.B. Investigative Actions. Moscow, Norma Publ., 2018. 240 p. (in Russian).

9. Sementsov V.A. Investigative Actions in PreTrial Proceedings. Moscow, Yurlitinform Publ., 2017. 254 p. (in Russian).

10. Smirnov A.V. Models of Criminal Procedure. Saint Petersburg, Nauka Publ., 2000. 224 p. (in Russian).
11. Spasovich V.D. Selected Works and Speeches. Tula, Autograph Publ., 2000. 496 p. (in Russian).

12. Strogovich M.S. Course of the Soviet Criminal Process. Vol. 1. Moscow, Nauka Publ., 1968. 330 p. (in Russian).

13. Schaefer S.A. Pre-Trial Proceedings in Russia: Stages of Development of Investigative, Judicial and Prosecutorial Authorities. Moscow, Norma Publ., 2013. 192 p. (in Russian).

14. Schaefer S.A. Investigations. System and Procedural Form. Moscow, Yurlitinform Publ., 2001. 208 p. (in Russian).

15. Schaefer S.A. The Essence and Methods of Collecting Evidence in the Soviet Criminal Process. Moscow, VYuZI Publishing house, 1972. 130 p. (in Russian).

\section{Information about the Author}

Valentina A. Lazareva, Doctor of Sciences (Jurisprudence), Professor, Department of Criminal Procedure and Criminalistics, Samara National Research University named after Academician S.P. Korolev, Akademika Pavlova St., 1, 443011 Samara, Russian Federation, v.a.Lazareva@mail.ru, https://orcid.org/0000-0003-2725-9517

\section{Информация об авторе}

Валентина Александровна Лазарева, доктор юридических наук, профессор кафедры уголовного процесса и криминалистики, Самарский национальный исследовательский университет им. акад. С.П. Королева, ул. Академика Павлова, 1, 443011 г. Самара, Российская Федерация, v.a.Lazareva@mail.ru,https://orcid.org/0000-0003-2725-9517 